\title{
correspondence
}

\section{Comment on 'Howyland'}

I $\mathrm{n}$ his recent editorial, Howy Jacobs raises the issue of the amount of time and money wasted to compile, evaluate and administrate research grants [1]. This waste of valuable resources has indeed reached such excessive levels that only strong and continuous criticism from scientists, research institutions, learned academies and academic journals will stand any chance of reversing the trend. It might also be time to restate a vision of science as furthering freedom, humanism and progress both within research and to the public.

This could take place as an international conference on academic freedom and creativity in the natural and social sciences. It would need to bring together natural scientists with scholars from the social, political and philosophical sciences, to analyse critically the history and organization of the sciences and the present system of funding research in the light of the relationship between science and society. Most of the criticism from scientists about the bureaucracy and narrow utilitarianism of science management fails to understand the origins and the idiosyncrasy of the current system, and why and how such an irrational and wasteful system continues to thrive $[1,2]$. It would thus be of interest to determine whether the issue of research funding is only a small part of a broader picture, and whether the apparent irrationality in the bureaucratic management of science follows rules that are rational within this framework.

Natural scientists who propose alternatives to the system often emphasize the role of the individual creative scientist who should be given more time and freedom [1-4], and who should be funded only on the basis of excellence and past achievements. A conference could similarly try to determine whether this is indeed the most efficient way to support research, or whether it merely takes for granted the application of underlying principles of competition. In an editorial on communication and cooperation in the Journal of the Federation of American Societies for Experimental Biology, Gerald Weissmann referred to Prince Pyotr Kropotkin (1842-1921) whose scientific and philosophical work emphasized the importance of mutual aid and cooperation in evolutionary biology and in human affairs $[5,6]$. It would be worthwhile to incite a debate among natural scientists about whether scientific success requires not only individual creativity and freedom, but also mutual interactions and cooperative creativity. The focus on individually centred research projects is, intentionally or not, systematically ignoring communication and cooperation in research and the possibility of collective funding. Community funding or community sharing of funds, at the level of laboratories, institutes and organizations, are alternatives that can also promote individual freedom, exploration of new ideas and risk-taking. The 'Howyland' that does not yet exist should aim to create not only fairness for individual researchers in science-funding schemes, but also research solidarity and collective funding.

CONFLICT OF INTEREST

The author declares that he has no conflict of interest.

\section{REFERENCES}

1. Jacobs H (2013) EMBO Rep 14: 481

2. Couée I (2013) EMBO Rep 14: 222-225

3. Kneissl D, Schwarz H (2011) Angew Chem Int Ed Eng/ 50: 12370-12371

4. Ioannidis JPA (2011) Nature 477: 529-531

5. Weissmann G (2009) FASEB / 23: 973-977

6. Kropotkin P (1902) Mutual Aid: A Factor of Evolution. 1972 Edn. New York University Press

\section{Ivan Couée is at the Ecobio (Ecosystems-}

Biodiversity-Evolution) Laboratory, Université de Rennes 1/CNRS, in Rennes, France.

E-mail:ivan.couee@univ-rennes1.fr

EMBO reports (2013) 14, 670; published online

12 July 2013; doi:10.1038/embor.2013.100 